\title{
Oxidation Through Coating Cracks of SiC-Protected Carbon/Carbon
}

Nathan S. Jacobson* and Don J. Roth

National Aeronautics and Space Administration, Glenn Research Center, Cleveland, Ohio 44135

*E-mail: Nathan.S.Jacobson@nasa.gov

Richard W. Rauser

University of Toledo, Toledo, Ohio 43606

Donald M. Curry

National Aeronautics and Space Administration, Johnson Space Center, Houston, Texas 77058 


\begin{abstract}
The oxidation of SiC-protected carbon/carbon through machined slots and naturally occurring craze cracks in the $\mathrm{SiC}$ was studied. The slot and crack geometries were characterized, and the subsurface oxidation of the carbon/carbon substrate at temperatures of 1000 to $1300{ }^{\circ} \mathrm{C}$ in air was assessed using weight change, x-ray computed tomography, and optical microscopy of sections. Rate constants were derived from these measurements and compared with a two-step diffusion control model of carbon oxidation. Oxidation kinetic measurements on both the specimens with machined slots and with naturally occurring craze cracks showed good agreement with the model.
\end{abstract}

Keywords: Carbon/carbon; Oxidation 


\section{Introduction}

\section{Reinforced Carbon/Carbon}

Fig. 1 is a schematic of reinforced carbon/carbon (RCC) with a SiC conversion coating used on the Space Shuttle Orbiter nose cap and wing leading edges. The material is made with a two-dimensional layup of carbon-carbon fabric with repeated applications of a liquid carbon precursor to fill voids [1]. The resultant high strength and light weight make it an ideal aerospace material; however, oxidation is a major concern. An oxidation protection system is based on a $\mathrm{SiC}$ conversion coating. Because of the difference in coefficient of thermal expansion (CTE) of the SiC coating and carbon/carbon substrate, the $\mathrm{SiC}$ coating shrinks more than the underlying carbon/carbon on cooldown from the coating application temperature. This leads to vertical cracks in the coating, and these cracks are pathways for oxygen to reach the carbon/carbon substrate. Actual RCC used on the orbiters contains glass sealants to plug the cracks; however, this work examines carbon/carbon with only SiC.

The crack morphologies in a similar system have been thoroughly characterized in an elegant study by Yurgartis et al. [2]. Both surface (plan) views and section views of the material were taken to obtain information such as crack spacing, crack width, and crack morphology. Such parameters were obtained for RCC in this study and prove critical to modeling oxidation. Buchanan and Little [3] have also characterized the crack pattern in a range of $\mathrm{SiC}$ coatings on carbon/carbon at various deposition conditions.

\section{Oxidation Through Coating Cracks}

Fig. 2 illustrates a typical oxidation void formed because of oxygen diffusion through a coating crack and subsequent reaction. A recent study by the authors outlines the microstructural features which distinguish this void from a processing void [4]. In general, an oxidation void is associated with a path for oxygen ingress (i.e., the crack in Fig. 2). At higher temperatures $\left(>1000^{\circ} \mathrm{C}\right)$ these oxidation processes are expected to be diffusion controlled. Diffusion control implies a lack of preferential oxidative attack and hence uniform attack of the carbon/carbon with a plane interface at the void boundary, as illustrated in Fig. 1. However, a close examination of the void in Fig. 2 indicates some preferential attack along fiber edges and the resultant "pointed fibers," which are characteristic of reaction control [5]. Thus the actual process is a mix of diffusion and reaction control. It will be shown that diffusion control dominates.

There are numerous studies of carbon oxidation through cracks and fissures in the protective coating and associated models found in the literature. Medford [6] developed models of oxidation for RCC, assuming pathways for oxygen are the cracks and fissures in $\mathrm{SiC}$. His model encompasses the following processes:

(1) Diffusion of oxygen inward through the cracks and/or fissures in the $\mathrm{SiC}$

(2) Oxidation of $\mathrm{SiC}$ crack walls to form $\mathrm{SiO}_{2}$

(3) Oxidation of carbon/carbon-matrix, fibers, or both

(4) Diffusion of $\mathrm{CO}$ outward through the cracks/fissures in the $\mathrm{SiC}$

Medford developed total mass change expressions based on these processes. The expressions were the diffusion equations with modifications for the area of reaction. First he examined the case below $982{ }^{\circ} \mathrm{C}$, where passive oxidation of the $\mathrm{SiC}$ is thought to be negligible; then he examined the case above $982{ }^{\circ} \mathrm{C}$, where passive oxidation of the $\mathrm{SiC}$ is thought to be significant.

The general process of carbon oxidation in a nonreactive matrix or through a nonreactive coating has been explored by several investigators [7]-[12]. Carbon oxidizes to $\mathrm{CO}(\mathrm{g})$ :

$$
\mathrm{C}(\mathrm{s})+1 / 2 \mathrm{O}_{2}(\mathrm{~g})=\mathrm{CO}(\mathrm{g})
$$

However, thermochemically the equilibrium between $\mathrm{O}_{2}, \mathrm{CO}$, and $\mathrm{CO}_{2}$ favors the products in the following reaction:

$$
1 / 2 \mathrm{O}_{2}(\mathrm{~g})+\mathrm{CO}(\mathrm{g})=\mathrm{CO}_{2}(\mathrm{~g})
$$

Thus $\mathrm{O}_{2}(\mathrm{~g})$ and $\mathrm{CO}(\mathrm{g})$ cannot coexist in similar amounts - they immediately will react to form $\mathrm{CO}_{2}(\mathrm{~g})$. However, the pairs of species in reaction (2), $\mathrm{CO}(\mathrm{g})$ with $\mathrm{CO}_{2}(\mathrm{~g})$ and $\mathrm{O}_{2}(\mathrm{~g})$ with $\mathrm{CO}_{2}(\mathrm{~g})$, may coexist. Thus a two-step oxidation process is required to model carbon oxidation. The two reactions are

\section{At the carbon/gas interface:}




$$
\mathrm{C}(\mathrm{s})+\mathrm{CO}_{2}(\mathrm{~g})=2 \mathrm{CO}(\mathrm{g})
$$

Note that $\mathrm{CO}_{2}(\mathrm{~g})$ is the oxidizing species.

2. At a distance away from the carbon/gas interface:

$$
\mathrm{CO}(\mathrm{g})+1 / 2 \mathrm{O}_{2}(\mathrm{~g})=\mathrm{CO}_{2}(\mathrm{~g})
$$

In an earlier paper [12], the authors adapted this two-step diffusion-controlled oxidation model to cylindrical pinholes in the conversion coating. Actual oxidation damage was assessed with weight loss measurements and area measurement of oxidation voids below the pinholes, using cross sections. At 1400 and $1000{ }^{\circ} \mathrm{C}$ hemispherical voids were observed on a macroscopic scale, indicating uniform attack and diffusion control. The two-step model described the process reasonably well at 1400 and $1000{ }^{\circ} \mathrm{C}$. However, at $600{ }^{\circ} \mathrm{C}$ only minimal oxidation is measured, and reaction control dominated. Hence the model did not fit at this lower temperature.

In the present study, the two-step oxidation model is further extended to describe a half-cylinder trough which forms under a slot or craze crack in the $\mathrm{SiC}$ coating. First a series of experiments is performed using machined slots in the coating. This allows testing the model with well-defined oxygen pathway geometry. Then the study is extended to actual through-thickness craze cracks in the coating. Oxidation damage is assessed with cross-sectional views, interrupted or real-time weight loss measurements, and x-ray computed tomography scans. The kinetics of carbon consumption is then compared with the model.

\section{Experimental}

Characterization of Slots and Cracks in Test Specimens

The tests described here were done on 1.91-cm-diameter RCC disks with a SiC coating on all sides. These disks were obtained from Lockheed-Martin Missiles and Fire Control in Dallas, Texas. Two sets of experiments were completed. Specimens with machined slots were used for the first set; specimens with naturally occurring craze cracks were used for the second set. Prior to oxidation, both types of specimens were characterized in order to quantify the area of exposed carbon.

In the first set of specimens, artificial craze cracks with well-defined geometries were made with diamond blades (Keen Kut Products, Hayward, CA) of 0.25, 0.51, 0.76, and $1.02 \mathrm{~mm}$ thicknesses. These slots were cut to the $\mathrm{SiC} /$ carbon-carbon interface. These slotted specimens are shown in Fig. 3. One slot was cut in each specimen where the oxidation kinetics was followed with weight losses; however, two slots of different dimensions were cut in the specimens where the kinetics was followed using microstructure examination and/or x-ray computed tomography. Slot dimensions were carefully measured with a traveling microscope as well as directly from the cross sections and reported in the results section. Total coating thicknesses were measured from cross sections. Because of the variation in coating thickness, 20 random measurements were taken and averaged.

The second set of specimens contained only the naturally occurring craze cracks. These were characterized with techniques similar to Yurgartis et al. [2]. Examination of the surface (plan view) did not reveal the complete crack pattern; however, grinding $\sim 300 \mu \mathrm{m}$ of SiC clearly revealed the crack pattern, which was then traced, as illustrated in Figs. 4(a) and (b). Image analysis software (Adobe Photoshop CS2 (Adobe Systems, Inc., San Jose, CA) with Fovea Pro 4.0 (Reindeer Graphics, Asheville, NC)) was used to determine the total crack length per unit area. The view of a section, as shown in Fig. 5, allowed measurements of crack width at room temperature. Several such sections were examined, and an average of 10 measurements is reported.

The measured values are listed in Table I and compared to the values reported by Yugartis et al. [2] and Buchanan and Little [3]. "Specimen A" of Yurgartis et al. is SiC-coated carbon/carbon with no matrix inhibitor; "Specimen B" is SiC-coated carbon/carbon with a boron-based matrix inhibitor. It should be noted that the materials examined by Yugartis et al. [2] and Buchanan and Little [3] are different from the RCC materials in this study. Here, the RCC had a thicker SiC coating applied by a pack cementation process than the other specimens in which the coating was applied by a chemical vapor deposition process. Yugartis et al. examined cracks that do and do not transverse the entire coating thickness. In this study only through-thickness cracks are examined. Differences in the specific CTE of carbon/carbon and the applied coating would be expected to have a major effect on the crack parameters. Thus the differences listed in Table I are not unexpected. It is interesting that despite the differences in crack width and spacing, the ratio of the exposed area of carbon to the surface area of the sample is roughly the same for all materials. 


\section{Oxidation Treatments and Sample Analyses}

The samples were oxidized in air in either a box furnace or a vertical tube furnace. The kinetics of the box furnace exposures were followed with weight measurements every $0.5 \mathrm{~h}$ for a total of $2.5 \mathrm{~h}$ at $1200{ }^{\circ} \mathrm{C}$. The craze crack specimens were suspended from a Cahn $\mathrm{C}-1000$ (Cahn Instruments, Cerritos, CA) recording electrobalance by a sapphire fiber with a platinum wire basket into the vertical tube furnace. To avoid platinum silicide formation, the platinum wire was lined with alumina beads. Bottled air at $1 \mathrm{~atm}(101325 \mathrm{~Pa})$ was used at a flow rate of $1.67 \times 10^{-3}$ liter/s, and isothermal oxidation tests were performed at $1000,1100,1200$, and $1300{ }^{\circ} \mathrm{C}$.

Selected samples were mounted and sectioned for optical microscopy to obtain measurements of oxidation void size. A specialized sample preparation procedure involved a premount of the entire sample in epoxy. A standard vacuum infiltration was done followed by a high-pressure application to fill the open porosity. Then the sample was sectioned, remounted in a standard metallographic mold, and polished with diamond pastes. This ensured clear microstructures and preserved the interface between the $\mathrm{SiC}$ and the carbon/carbon.

$\mathrm{X}$-ray computed tomography $(\mathrm{CT})$ was used to provide additional images of the oxidation damage, without sectioning. This SmartScan Model 100 (CITA Systems, Inc., Pueblo, CA) system utilizes a Feinfocus FXE-160 (COMET AG, Flamatt, Switzerland) microfocus X-ray source to produce very high-resolution imaging of samples, approaching $25 \mu \mathrm{m}$, in the CT mode of operation. The major hardware components of this system included the x-ray source, an area detector system, a five-axis object positioning subassembly, and a lead-lined radiation cabinet. A dual-processor computer system controlled the data acquisition and image processing. The slice plane thickness was $120 \mu \mathrm{m}$ per slice for these samples. Putting together slices electronically gave a three-dimensional view of oxidation damage.

\section{Oxidation Model Adapted to Slots and Cracks}

Fig. 6 is a schematic of the two-step diffusion-controlled model for oxidation through a pore or crack. Note that $\mathrm{CO}_{2}$ is the oxidizer and reaction (3) occurs at position $x=0$ whereas reaction (4) occurs at position $x=x_{f}$. A list of symbols used in this report is in the appendix to aid the reader.

The molar flux, $J_{i}$, of each species, $i$, is defined by

$$
J_{i}=D_{i}^{\mathrm{eff}}\left(\frac{\partial c_{i}}{\partial x}\right)+v_{i}^{\mathrm{ave}} c_{i}
$$

The first term is the diffusive term and the second is the convective term. Here $D_{i, \text { eff }}$ is the effective gas phase diffusivity, $c_{i}$ is the molar concentration of species $i\left(i=\mathrm{CO}, \mathrm{CO}_{2}\right.$, or $\left.\mathrm{O}_{2}\right)$, and $x$ is the distance down the slot or crack. The average molar velocity $v_{i}^{\text {ave }}$ is defined as

$$
v_{i}^{\mathrm{ave}}=\frac{\sum_{i} c_{i} v_{i}}{\sum_{i} c_{i}}=\frac{\sum_{i} J_{i}}{c_{T}}
$$

Here $c_{T}$ is the sum of concentrations. Equation (5) becomes

$$
J_{i}=D_{i}^{e f f}\left(\frac{\partial c_{i}}{\partial x}\right)+\frac{c_{i}}{c_{T}} \sum_{i} J_{i}
$$

The boundary conditions are shown in Fig. 6(b):

$$
\begin{gathered}
\text { At } x=0: \quad c_{\mathrm{CO}}=c_{\mathrm{CO}}^{0} \quad c_{\mathrm{CO}_{2}}=c_{\mathrm{CO}_{2}}^{0} \\
\text { At } x=x_{f}: \quad c_{\mathrm{CO}_{2}}=c_{\mathrm{CO}_{2}}^{*} \quad c_{\mathrm{O}_{2}}=c_{\mathrm{CO}}=0
\end{gathered}
$$




$$
\text { At } x=L: \quad c_{\mathrm{O}_{2}}=c_{\mathrm{O}_{2}}^{L} \quad c_{\mathrm{CO}_{2}}=0
$$

As shown in Fig. 6(b) $L$ is the total crack depth, which is the coating thickness.

Consider the fluxes in Region 1 (Fig. 6(a)). Here $J_{\mathrm{O}_{2}}^{\mathrm{I}}=-J_{\mathrm{CO}_{2}}^{\mathrm{I}}$ and hence the convective term in equation (7) is zero. The fluxes of $\mathrm{O}_{2}(\mathrm{~g})$ and $\mathrm{CO}_{2}(\mathrm{~g})$ in this region are thus calculated as

$$
\begin{gathered}
J_{\mathrm{O}_{2}}^{\mathrm{I}}=-D_{\mathrm{O}_{2}}\left(\frac{\partial c_{\mathrm{O}_{2}}}{\partial x}\right)=\frac{-D_{\mathrm{O}_{2}} c_{\mathrm{O}_{2}}^{L}}{\left(L-x_{f}\right)} \\
J_{\mathrm{CO}_{2}}^{\mathrm{I}}=D_{\mathrm{CO}_{2}}\left(\frac{\partial c_{\mathrm{CO}_{2}}}{\partial x}\right)=\frac{D_{\mathrm{CO}_{2}} c_{\mathrm{CO}_{2}}^{*}}{\left(L-x_{f}\right)}
\end{gathered}
$$

A determination of the $\mathrm{CO}_{2}$ flux emerging from the crack or slot, $J_{\mathrm{CO}_{2}}^{\mathrm{I}}$, is the ultimate goal, because it is a measure of carbon consumption. First the quantity $x_{f}$ is needed. This can only be obtained as the ratio $x_{f} / L$, which is derived from the following equations (eqs. (10) to (17)). The two fluxes in equation (9) are equal and opposite. From this fact, one can deduce the concentration gradients in Fig. 6(b). The concentration of $\mathrm{CO}_{2}$ at $x=x_{f}$ is

$$
c_{\mathrm{CO}_{2}}^{*}=\frac{D_{\mathrm{O}_{2}} c_{\mathrm{O}_{2}}^{L}}{D_{\mathrm{CO}_{2}}}
$$

Equation (7) for $\mathrm{CO}$ and $\mathrm{CO}_{2}$ in Region II (Fig. 6(a)) is more complex, as now there is a convection term since the stoichiometry of reaction (3) requires

$$
J_{\mathrm{CO}}^{\mathrm{II}}=-2 J_{\mathrm{CO}_{2}}^{\mathrm{II}}
$$

Thus equation (7) for $\mathrm{CO}_{2}$ becomes

$$
J_{\mathrm{CO}_{2}}^{\mathrm{II}}=-D_{\mathrm{CO}_{2}}\left(\frac{\partial c_{\mathrm{CO}_{2}}}{\partial x}\right)-\frac{c_{\mathrm{CO}_{2}} J_{\mathrm{CO}_{2}}^{\mathrm{II}}}{c_{T}}
$$

Rearranging to separate variables gives

$$
J_{\mathrm{CO}_{2}}^{\mathrm{II}} \mathrm{d} x=-D_{\mathrm{CO}_{2}}\left(\frac{c_{T}}{c_{T}+c_{\mathrm{CO}_{2}}}\right) \mathrm{d} c_{\mathrm{CO}_{2}}
$$

This can be integrated from $c_{\mathrm{CO}_{2}}=c_{\mathrm{CO}_{2}}^{*}$ at $x=x_{f}$ and $c_{\mathrm{CO}_{2}}=c_{\mathrm{CO}_{2}}^{0}$ at $x=0$ :

$$
J_{\mathrm{CO}_{2}}^{\mathrm{II}}=\frac{-D_{\mathrm{CO}_{2}} c_{T}}{x_{f}} \ln \left(\frac{c_{T}+c_{\mathrm{CO}_{2}}^{*}}{c_{T}+c_{\mathrm{CO}_{2}}^{0}}\right)
$$

This can be simplified further using equation (10) and the fact that $c_{\mathrm{CO}_{2}}^{*}>>c_{\mathrm{CO}_{2}}^{0}$ :

$$
J_{\mathrm{CO}_{2}}^{\mathrm{II}}=\frac{-D_{\mathrm{CO}_{2}} c_{T}}{x_{f}} \ln \left(1+\frac{D_{\mathrm{O}_{2}} c_{\mathrm{O}_{2}}^{L}}{D_{\mathrm{CO}_{2}} c_{T}}\right)
$$


A mass balance between $\mathrm{CO}$ and $\mathrm{O}_{2}$ gives

$$
J_{\mathrm{CO}}^{\mathrm{II}}=-2 J_{\mathrm{O}_{2}}^{\mathrm{I}}
$$

Combining this with equation (11),

$$
J_{\mathrm{CO}_{2}}^{\mathrm{II}}=J_{\mathrm{O}_{2}}^{\mathrm{I}}
$$

When equation (15) is combined with equations (17) and (9a),

$$
J_{\mathrm{CO}_{2}}^{\mathrm{II}}=\frac{-D_{\mathrm{O}_{2}} c_{\mathrm{O}_{2}}^{L}}{\left(L-x_{f}\right)}=\frac{-D_{\mathrm{CO}_{2}} c_{T}}{x_{f}} \ln \left(1+\frac{D_{\mathrm{O}_{2}} c_{\mathrm{O}_{2}}^{L}}{D_{\mathrm{CO}_{2}} c_{T}}\right)
$$

Solving for $L / x_{f}$ gives

$$
\frac{L}{x_{f}}=1+\frac{D_{\mathrm{CO}_{2}} c_{\mathrm{O}_{2}}^{L}}{D_{\mathrm{O}_{2}} c_{T}}\left[\ln \left(1+\frac{D_{\mathrm{O}_{2}} c_{\mathrm{O}_{2}}^{L}}{D_{\mathrm{CO}_{2}} c_{T}}\right)\right]^{-1}
$$

Next the gas phase diffusivities, $D_{i, \mathrm{~N}_{2}}$, of $\mathrm{O}_{2}$ in $\mathrm{N}_{2}$ and $\mathrm{CO}_{2}$ in $\mathrm{N}_{2}$ must be estimated. This is done with the Chapman-Enskog correlation [13], which yields diffusivity in $\mathrm{cm}^{2} / \mathrm{s}$ when the variables in the expression below are expressed in the appropriate units:

$$
D_{i, \mathrm{~N}_{2}}=0.0018583\left(\frac{1}{M_{i}}+\frac{1}{M_{\mathrm{N}_{2}}}\right)^{1 / 2} T^{3 / 2}\left(\frac{1}{P \sigma_{i, \mathrm{~N}_{2}}^{2} \Omega}\right)
$$

Here $M_{i}$ is the molecular weight $(\mathrm{g} / \mathrm{mol})$ of species $i, T$ is the absolute temperature $(\mathrm{K}), P$ is the pressure (atm), $\sigma_{i, \mathrm{~N}_{2}}$ is the average of the molecular diameter ( $\AA$ ) of species $i$ and $\mathrm{N}_{2}$, and $\Omega_{i, \mathrm{~N}_{2}}$ is the collision integral (unitless). The later two were determined from the tables of Svehla [14] and Sherwood et al. [15]. Table II lists some calculated diffusivities. The value of $L / x_{f}$ is also shown in Table II and is constant with temperature.

For narrow cracks, the contribution of Knudsen diffusion must also be considered. In the Knudsen diffusion regime, molecule-wall collisions dominate over molecule-molecule collisions. The effective diffusivity, $D^{\text {eff }}$, is a combination of the ordinary diffusivity, $D^{\text {ord }}$, and Knudsen diffusivity, $D^{K}$. The Knudsen diffusivity can be estimated for a pore as [16]

$$
D_{i}^{k}=(9.7)\left(10^{3}\right) q \sqrt{\frac{T}{M_{i}}}
$$

Here $q$ is the pore radius in centimeters. Equation (21) is for a pore, not a crack, but it is still suitable for this general discussion of Knudsen effects. The combined effects of ordinary and Knudsen diffusion can be written as [17]

$$
\frac{1}{D^{\text {eff }}}=\frac{1}{D^{\text {ord }}}+\frac{1}{D^{k}}
$$

When the mean free path is greater than 10 crack widths, then Knudsen diffusion is the dominating flow mechanism [18]. For the $1 \mathrm{~atm}$ total pressure used in this study, the mean free path is $\sim 3.3 \times 10^{-7} \mathrm{~m}$. The machined slots are much larger than this, and even the craze cracks $\left(\sim 1.28 \times 10^{-5} \mathrm{~m}\right)$ are larger than the mean free path. This becomes apparent by comparing $D^{\text {ord }} / D^{\text {eff }}$ to the pore diameter, as shown in Fig. 7 . The level parts of the plots show $D^{\text {eff }}=D^{\text {ord }}$. At the 
$1 \mathrm{~atm}(101325 \mathrm{~Pa})$ pressure used in this study, the average crack width indicates a very small Knudsen contribution; however, at lower pressures which are closer to actual reentry pressure, the Knudsen contribution must be considered.

Now with values for $x_{f} / L$ and the gas phase diffusivities carbon consumption can be calculated. As noted, this is simply the molar flux of $\mathrm{CO}_{2}(\mathrm{~g})$ emerging from the crack, as given by equations (9b) and (9a):

$$
J_{\mathrm{CO}_{2}}^{\mathrm{I}}=\frac{D_{\mathrm{CO}_{2}} c_{\mathrm{CO}_{2}}^{*}}{\left(L-x_{f}\right)}=\frac{D_{\mathrm{O}_{2}} c_{\mathrm{O}_{2}}^{L}}{L\left[1-\left(\frac{x_{f}}{L}\right)\right]}
$$

The denominator is written in the above form, since $x_{f} / L$ is now a known quantity. The goal is to estimate the radius of the cavity formed below a crack, as shown in Fig. 6.

The flux of $\mathrm{CO}_{2}$ (g) (eq. (11)) can be converted to a mass loss of carbon as

$$
\frac{\mathrm{d} W_{\mathrm{C}}}{\mathrm{d} t}=M_{\mathrm{C}} J_{\mathrm{CO}_{2}}^{\mathrm{I}} w l=\frac{M_{\mathrm{C}} D_{\mathrm{O}_{2}} P_{\mathrm{O}_{2}} w l}{R T L\left[1-\left(\frac{x_{f}}{L}\right)\right]}
$$

Here $W_{\mathrm{C}}$ is the weight loss of carbon, $M_{\mathrm{C}}$ is the molecular weight of carbon $(12 \mathrm{gm} / \mathrm{mol}), R$ is the gas constant, $w$ is the crack width, and $l$ is the crack length. Note that the $w l$ term would be omitted for weight loss per unit area.

The weight loss with time can be related to the volume change with time of the cavity at the base of the crack. Assume a rectangular crack with a half-cylinder cavity of radius $r$ growing at its base. In practice the nonideality of the crack is accounted for with a "tortuosity factor" [19]. For this approximation a tortuosity factor of 1 is assumed.

The weight loss can be related to the radius of the growing half-cylinder cavity as

$$
\frac{\mathrm{d} W_{\mathrm{C}}}{\mathrm{d} t}=\rho \frac{\mathrm{d} V}{\mathrm{~d} t}=\rho\left[\frac{\mathrm{d}\left(\frac{\pi r^{2} l}{2}\right)}{\mathrm{d} t}\right]
$$

Here $r$ is the radius of the half cylinder and $\rho$ is the density of carbon/carbon taken to be $1.362 \mathrm{~g} / \mathrm{cm}^{3}$ [20]. Equating equations (24) and (25) and separating variables gives

$$
\mathrm{d}\left(\frac{\pi r^{2} l}{2}\right)=\frac{M_{\mathrm{C}} D_{\mathrm{O}_{2}} P_{\mathrm{O}_{2}} w l \mathrm{~d} t}{\rho R T L\left[1-\left(\frac{x_{f}}{L}\right)\right]}
$$

Integrating and solving for $r$ results in the following:

$$
r=\sqrt{\frac{2 M_{\mathrm{C}} D_{\mathrm{O}_{2}} P_{\mathrm{O}_{2}} w t}{\pi \rho R T L\left[1-\left(\frac{x_{f}}{L}\right)\right]}}
$$

Note the crack length cancels out and does not appear in the final expression. Equations (24) and (27) are the key equations used to calculate oxidation damage in subsequent sections.

An important consideration is the variation of the crack width with temperature. This is minor for the machined slots, but significant for the craze cracks. The actual coating is not dense $\mathrm{SiC}$, but rather converted carbon-carbon fibers and carbon matrix material. For this approximation the accepted coefficient of thermal expansion (CTE) for $\mathrm{SiC}$ as $\sim 6.1 \times 10^{-6} \mathrm{~K}^{-1}$ is used [21]. The thermal expansion along a carbon fiber is taken as $1 \times 10^{-6} \mathrm{~K}^{-1}$ [22]. This puts 
the coating in tension on cooldown, which leads to the cracks during processing. However, it leads to compression and possible crack closing during heatup to temperatures above the processing temperature. The extent of crack closure can be estimated as

$$
W_{R T}=\Delta \alpha s\left(T_{P}-T\right)
$$

Here $W_{R T}$ is the crack width at room temperature, $\Delta \alpha$ is the difference between the CTE of SiC and that of the carbon/carbon, $s$ is the crack spacing, $T_{P}$ is the processing temperature (taken as $\sim 1650{ }^{\circ} \mathrm{C}$ ), and $T$ is the operating temperature. Since the crack width at room temperature is $12.8 \pm 1.4 \mu \mathrm{m}$, the crack spacing is calculated to be $1.5 \pm 0.2$ $\mathrm{mm}$ from the equation above, reasonably close to that measured given the approximation of the CTEs. This calculated crack spacing is used in the above equation to estimate crack width at the oxidation temperature. At 1200 ${ }^{\circ} \mathrm{C}$ the crack width was calculated to be $7.1 \mu \mathrm{m}$.

Oxidation along the $\mathrm{SiC}$ crack wall may affect the rate of carbon/carbon oxidation. As will be discussed, the samples gain considerable weight due to passive oxidation. Microscopy indicates that thin films of $\mathrm{SiO}_{2}$ form on both the internal and external surfaces of the SiC coating. Fig. 8 shows the mouth of a crack and only a thin $(\sim 0.25-$ $\mu \mathrm{m})$ film of $\mathrm{SiO}_{2}$.

On the basis of the thin films of oxide observed, the oxidation rate constants for high-purity chemically vapor deposited (CVD) SiC [23] are used. The results shown in Table III are somewhat lower than the thicknesses of the oxide film on both the slots and cracks. It is probable the lower purity $\mathrm{SiC}$ in the conversion coating has an oxidation rate constant of an order of magnitude or so greater than that of CVD SiC. Such behavior is well documented [24]. Nonetheless images such as those in Fig. 8 indicate that under the conditions of this study, crack closure due to wall oxidation can be neglected.

\section{Results and Discussion: Measured Oxidation Kinetics and Comparison With Model Oxidation Below Machined Slots in SiC Coating}

Initially, two specimens were oxidized at $1200^{\circ} \mathrm{C}$ and examined with both $\mathrm{CT}$ and optical microscopy. One specimen had nominal 0.25 - and $0.51-\mathrm{mm}$ slots machined in the face. The other specimen had nominal 0.76- and 1.01-mm slots machined in the face. Cross-sectional micrographs for the cavities formed below the nominal $0.25-\mathrm{mm}$ slots are shown in Figs. 9(a) and (b). Oxidation damage below all slots exhibited this type of half-cylinder morphology. Figs. 10(a) and (b) show the x-ray CT information.

The data in Figs. 9 and 10 make several important points. The similarity between the CT images and the actual optical microscopy images give credibility to the use of CT imaging to precisely size and characterize the threedimensional morphology of this type of oxidation damage [25]. Both the optical microscope images and the CT images indicated the oxidation damage occurs in the form of a half cylinder. On a macroscopic scale this indicates even attack in all directions, supporting diffusion control of the oxidation process and the use of a half cylinder in the model.

Using image analysis software the areas of the oxidation cavities were measured. Approximating these areas as semicircles allows calculation of effective radii. The experimental results are compared to the predictions from equation (27) in Table IV. The error in the predicted oxidation slot radius values is due to uncertainty in the measurement of the slot widths. Agreement between the measured and predicted cavity radius is within a factor of 0.45 to 0.62 . All the measurements are consistently lower than the predictions, which is likely due to carbon consumption beyond the apparent boundaries of the half cylinder, as seen clearly in Fig. 9(b).

A second set of experiments was done to follow the kinetics of oxidation below machined slots with weight loss as the indicator of oxidation damage. In this case specimens with only a single slot were used. Kinetics were followed using interrupted weight loss measurements. A typical kinetic curve is shown in Fig. 11. Note there is an initial weight gain, which is likely passive oxidation of the $\mathrm{SiC}$, followed by a weight loss. The passive oxidation of the $\mathrm{SiC}$ will be discussed in the following section. The rates of weight loss are the carbon oxidation rates per the exposed area of carbon, which was determined from the slot dimensions. Table V compares the measured rates with those predicted. Rates are normalized per unit area of exposed carbon, and hence the predictions are all the same for the given temperature of $1200{ }^{\circ} \mathrm{C}$. The error in the predicted oxidation rate values is due to uncertainty in the measurement of slot depth (coating thickness). The error in the measured rate values is due to uncertainty in the measurements of slot width and length. Note that these errors make the measured rates for three of the four smaller slots within the limits of the predictions (Table V). For the larger width slots $(\sim 1 \mathrm{~mm})$, the measured rates are $\sim 0.33$ of the predicted. The reasons for this are not clear. 


\section{Oxidation Below Craze Cracks in the SiC Coating}

Having established the validity of the model with the machined slots, it is now appropriate to proceed to the more realistic situation of craze cracks in the $\mathrm{SiC}$ coating. Now there is a less well-defined geometry, as illustrated with the crack pattern in Fig. 4 and crack width measurement in Fig. 5. Nonetheless these measurements can be used to estimate approximate values for the diffusion model.

Oxidation kinetics for these specimens were followed with a recording thermobalance that enabled continuous weight change measurements. Results for $1000,1100,1200$, and $1300{ }^{\circ} \mathrm{C}$ are given in Figs. 12 (a) to (d). These data are reported in weight change per geometrical surface area. As will be discussed, the geometric surface area must be modified for actual reactive area of oxidation, which is different for each of the two processes occurring.

The oxidation kinetics suggest a combined parabolic/linear rate law. The initial weight gain observed at the three higher temperatures is likely due to the passive oxidation of $\mathrm{SiC}$, which is parabolic:

$$
\left(\frac{\Delta M}{A}\right)=\sqrt{k_{p} t}
$$

Here $\left(\frac{\Delta M}{A}\right)$ is the specific weight change (weight per unit area), $k_{p}$ is the parabolic rate constant, and $t$ is the time.

The specific weight change over the surface area $A$ of the $\mathrm{SiC}$ is taken as the geometric area of the sample disk. The weight loss after $\sim 0.5 \mathrm{~h}$ is linear with time and most likely due to carbon oxidation through the craze cracks. It is described by

$$
\left(\frac{\Delta M}{A^{\prime}}\right)=k_{l} t
$$

Here $k_{l}$ is the linear rate constant. Note that $A^{\prime}$ is the exposed area of carbon/carbon. This is the crack width at temperature multiplied by the total crack length for a particular sample.

The changes in the kinetic curves with temperature support the interpretation of the process as passive $\mathrm{SiC}$ oxidation coupled with $\mathrm{C} / \mathrm{C}$ oxidation. At $1000{ }^{\circ} \mathrm{C}$ the initial parabolic regime was not observed; however, at 1200 and $1300{ }^{\circ} \mathrm{C}$ it was quite evident. This is due to the fact that passive oxidation of $\mathrm{SiC}$ shows a strong dependence on temperature [23]. Note, however, that the linear rate constant is relatively temperature independent. Diffusioncontrolled oxidation of carbon shows only a weak temperature dependence, a combination of the $T^{1 / 2}$ dependence of the diffusion coefficient and the $T^{1}$ dependence of the crack closure due to thermal expansion. This dependence may not be evident in the limited data set in this study.

The combined passive oxidation of $\mathrm{SiC} /$ linear oxidation of carbon rate law is written as

$$
\left(\frac{\Delta M}{A}\right)_{\text {total }}=\sqrt{k_{p} t}+k_{l} t
$$

Here $\left(\frac{\Delta M}{A}\right)_{\text {total }}$ is the measured weight change per unit of geometrical area, $k_{p}$ is the parabolic rate constant, $t$ is the time, and $k_{l}$ is the linear rate constant. This expression is similar to that used to describe the combined oxidation/vaporization of chromium alloys [26] and $\mathrm{SiC}$ [27], but this is somewhat simpler in that there are two independent processes occurring.

The dashed lines in Figs. 12(a) to (d) are fits of equation (31) to each kinetic curve. From these fits the parabolic and linear rate constants can be derived. Fits to the linear region are good; fits to the parabolic region are only approximate because of such factors as changing surface areas of passive oxidation and passive oxidation internal to the coating, which are not included in equation (31). The parabolic and linear rate constants extracted from the fit to the kinetic data are given in Table VI. The parabolic rate constant was taken directly from the fit. Note that the listed parabolic rate constants are many orders of magnitude greater than those measured for high-purity $\mathrm{SiC}$ [23]. This is due to extensive internal oxidation of the porous $\mathrm{SiC}$ conversion coating. Measurements of the $\mathrm{SiC}$ conversion coating density have been reported to be $2.114 \mathrm{~g} / \mathrm{cm}^{3}$ [20]. When compared with the theoretical density of 3.217 $\mathrm{g} / \mathrm{cm}^{3}$ for $\mathrm{SiC}$, this indicates a high amount of porosity. This porosity leads to the large extent of internal oxidation. 
The linear rate constant shown in Table VI was taken from the fit and multiplied by the geometrical surface area. This gives a rate of carbon oxidation per area of exposed carbon/carbon and allows direct comparison to the calculated rate in Table VI. The predicted rates were obtained from equation (24).

The cracks in the $\mathrm{SiC}$ form a complex geometry. The oxidation cavities are an irregular shape as seen in the micrograph in Fig. 2. Fig. 13(a) shows the location of two CT scans, and Fig. 13(b) shows the results of the CT scans illustrating the varying size and shape of the oxidation cavity below a craze crack. The actual oxidation cavities are darker and are outlined in white in Fig. 13(b).

Despite this complex geometry of both the craze crack and the resultant oxidation damage, average values of crack width and length can be put into the oxidation model to estimate the rates. These are shown in Table VI. Experimental rates were found to be both greater and less than the predicted rates for the temperature range of 1000 to $1300{ }^{\circ} \mathrm{C}$. As in the case of the slots, the error associated with the predicted oxidation rate values is due to variation in the measurement of crack depth (coating thickness), and error associated with the measured rate values is primarily due to uncertainty in the crack length and width measurements. The predicted and measured rates show agreement within experimental error, which is remarkable given the irregular geometry of the cracks and corresponding oxidation damage as well as the approximations used in this study.

\section{Conclusions}

The kinetics of subsurface oxidation of SiC-protected reinforced carbon/carbon has been studied in the diffusion control regime (1000 to $1300{ }^{\circ} \mathrm{C}$ ) in air. Specimens with machined slots in the $\mathrm{SiC}$ coating as well as specimens with natural occurring craze cracks in the SiC coating were tested. The geometry of these oxidation pathways was characterized with the aim of obtaining the exposed area of the carbon/carbon. For the craze cracks, crack closure due to shrinkage was considered. Oxidation of the $\mathrm{SiC}$ walls was shown to be negligible under the conditions of this study. Oxidation damage of the carbon/carbon was assessed with weight changes, CT scans, and optical microscopy of sections. The CT scans confirm the idealized half-cylinder shape of the oxidation cavity in the case of a slot. A two-step diffusion control model for carbon oxidation is adapted to describe the growth kinetics of this half cylinder. Oxidation rates were first measured for the well-defined geometry of the slotted specimens. In the case of optical measurements of oxidation, the error associated with the predicted values of oxidation rate were primarily due to uncertainty in the measurements of the slot width, and the error in the measured rate values were due to uncertainty in measuring the size of the oxidation cavities. For these optical measurements, measured rates were consistently lower than the predicted by a factor ranging from 0.45 to 0.62 . For the weight loss measurements of oxidation, errors in the predictions were primarily due to errors in measuring the slot depth (coating thickness) and errors in the measurements were due to errors in measuring the slot width and length. Most of the predictions were within experimental error of the measurements, except for the largest slots ( 1 mm width), where the measurements differ by a factor of $\sim 0.33$ from the predictions. Proceeding next to the actual craze cracks, the oxidation cavity was found to be highly irregular and approximated by a half-cylinder shape. Weight loss was used to measure oxidation, and again, errors in the predictions were primarily due to errors in measuring the slot depth (coating thickness) and errors in the measurements were due to errors in measuring the crack width and length. For oxidation below craze cracks, the predictions are generally within the experimental error of the measurements. 


\section{Acknowledgments}

Helpful discussions with R.A. Rapp, G. Wang, and X. Zheng, formerly of The Ohio State University; T. Parathasarathy of UES, Inc.; and E. Opila of NASA Glenn Research Center are gratefully acknowledged. 


\section{References}

1. D.M.CURRY, J.W. LATCHEM, and G.B. WISENHUNT, in 21st AIAA Aerospace Sciences Meeting (AIAA, Reno, NV, 1983).

2. S.W. YURGARTIS, M.D. BUSH, and B.E. MAST, Surf. Coat. Tech. 70 (1994) 131.

3. F.J. BUCHANAN and J.A. LITTLE, Surf. Coat. Tech. 53 (1992) 137.

4. N.S. JACOBSON and D.M. CURRY, Carbon 44 (2006) 1142.

5. W.H. GLIME and J.D. CAWLEY, Carbon 33 (1995) 1053.

6. J.E. MEDFORD, in 10th AIAA Thermophysics Conference (AIAA, Denver, CO, 1975).

7. J. BERNSTEIN and T.B. KOGER, J. Electrochem. Soc. 135 (1988) 2086.

8. E.L. COURTRIGHT, J.T. PRATER, G.R. HOLCOMB, G.R. ST. PIERRE, and R.A. RAPP, Oxid. Met. 36 (1991) 423.

9. L. FILIPUZZI, G. CAMUS, R. NASLAIN, and J. THEBAULT, J. Am. Ceram. Soc. 77 (1994) 459.

10. L. FILIPUZZI and R. NASLAIN, J. Am. Ceram. Soc. 77 (1994) 467.

11. G.R. HOLCOMB, Corrosion 52 (1996) 531.

12. N.S. JACOBSON, T.A. LEONHARDT, D.M. CURRY, and R.A. RAPP, Carbon 37 (1999) 411.

13. G.H. GEIGER and D.R. POIRIER, in "Transport Phenomena in Metallurgy," (Addison-Wesley, Reading, MA, 1973) p. 464.

14. R.A. SVEHLA, NASA TR-R-132 (1962).

15. T.K. SHERWOOD, R.L. PIGFORD, and C.R. WILKE, "Mass Transfer," (McGraw-Hill, New York, NY, 1975$)$ p. 20.

16. C.J. GEANKOPLIS, "Mass Transport Phenomena" (Ohio State University Bookstores, Columbus, OH, 1984$),$ p. 152.

17. G.W. HEWITT, in "Chemistry and Physics of Carbon" (Marcel Dekker, New York, NY, 1965) p. 73.

18. J.L. MARGRAVE, in "Characterization of High Temperature Vapors," (Wiley, New York, NY, 1967) p. 126.

19. G.H. GEIGER and D.R. POIRIER, in "Transport Phenomena in Metallurgy,” (Addison-Wesley, Reading, MA, 1973) p. 468.

20. S.D. WILLIAMS, D.M. CURRY, D.C. CHAO, and V.T. PHAM, J. Thermophys. Heat Transfer, 9 (1995) 478.

21. Y.S. TOULOUKIAN, R.K. KIRBY, R.E. TAYLOR, and T.Y.R. LEE, in "Thermal Expansion Nonmetallic Solids" (IFI/Plenum, New York, NY, 1977) p. 873.

22. T. ULLMANN, M. SHMÜCKER, H. HALD, R. HENNE, and H. SCHNEIDER, in Proceedings of 8th International Symposium on Materials in a Space Environment (Archachon, Frankreich, June 2000).

23. L. OGBUJI and E.J. OPILA, J. Electrochem. Soc. 142 (1995) 925.

24. N.S. JACOBSON, J. Am. Ceram. 76 (1993) 3.

25. D.J. ROTH, N.S. JACOBSON, J.N GRAY, L.M. COSGRIFF, J.R. BODIS, R.A. WINCHESKI, R.W. RAUSER, E.A. BURNS, and M.S. MCQUARTER, Ceram. Eng. Sci. Proc. 26 (2006) 133.

26. C.S. TEDMON JR., J. Electrochem. Soc. 113 (1966) 766.

27. E.J. OPILA, JR. and N.S. JACOBSON, Oxid. Met. 44 (1995) 527. 


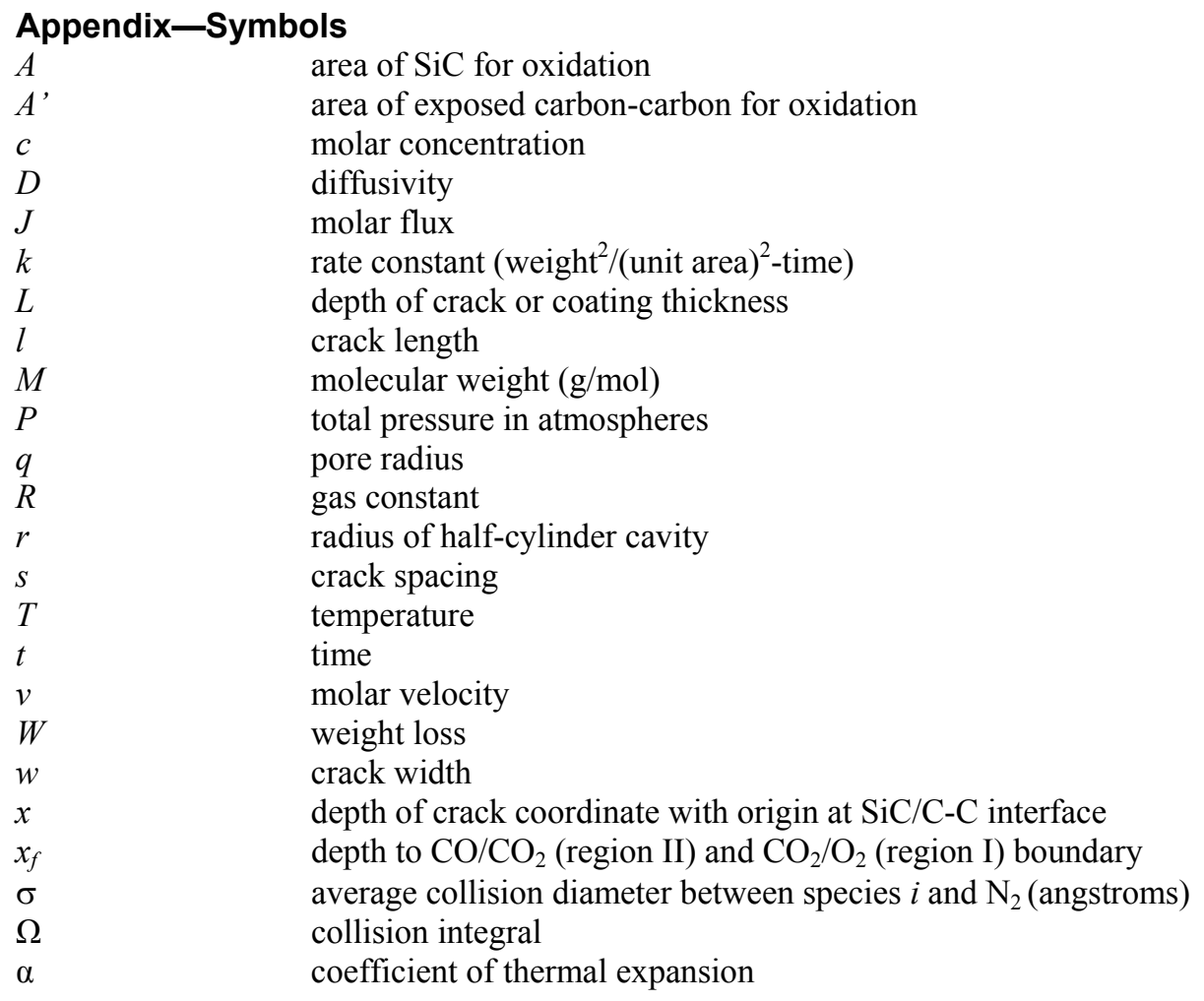

\section{Subscripts:}

$\begin{array}{ll}f & \text { indicates boundary of regions I and II } \\ i & \text { species } \\ l & \text { linear } \\ P & \text { processing } \\ p & \text { parabolic } \\ T & \text { total }\end{array}$

\section{Superscripts:}

ave

eff

K

$L$

ord

0

I

II average

effective

Knudsen

indicates position $L$

ordinary

indicates position 0

region I

region II

indicates position $x_{f}$ 
TABLE I Measured crack parameters for SiC-coated carbon/carbon materials

\begin{tabular}{lccccc}
\hline \multicolumn{1}{c}{$\begin{array}{c}\text { SiC-coated carbon/carbon } \\
\text { material }\end{array}$} & $\begin{array}{c}\text { Coating } \\
\text { thickness, } \\
\mathrm{mm}\end{array}$ & $\begin{array}{c}\text { Crack length per } \\
\text { unit area, } \\
\mathrm{mm}^{-1}\end{array}$ & $\begin{array}{c}\text { Crack spacing, } \\
\mathrm{mm}\end{array}$ & $\begin{array}{c}\text { Crack width, } \\
\mu \mathrm{m}\end{array}$ & $\begin{array}{c}\text { Crack area per } \\
\text { unit area }\end{array}$ \\
\hline Present study, RCC & $0.78 \pm 0.14$ & $0.33 \pm 0.04$ & $3.4 \pm 0.9$ & $12.8 \pm 1.41$ & $4.2 \times 10^{-3}$ \\
Yurgartis et al. [2], Specimen A & $0.3024 \pm 0.03866$ & 2.985 & $0.6247 \pm 0.2233^{\mathrm{a}}$ & $1.72 \pm 1.41$ & $5.1 \times 10^{-3}$ \\
Yurgartis et al. [2], Specimen B & $0.2788 \pm 0.02853$ & 3.555 & $0.6517 \pm 0.3356^{\mathrm{a}}$ & $2.02 \pm 1.47$ & $7.3 \times 10^{-3}$ \\
Buchanan and Little [3] & ---- & ---- & --- & --- & $(3-8) \times 10^{-4}$ \\
\hline
\end{tabular}

${ }^{a}$ Through coating thickness. 
TABLE II Diffusivities of $\mathrm{O}_{2}(\mathrm{~g})$ and $\mathrm{CO}_{2}(\mathrm{~g})$ in $\mathrm{N}_{2}(\mathrm{~g})$ and position of boundary between regions I and II (Fig. 6(a)).

\begin{tabular}{cccc}
\multicolumn{4}{c}{ [Total pressure is 1 atm (101325 Pa).] } \\
\hline $\begin{array}{c}\text { Temperature, } \\
{ }^{\circ} \mathrm{C}\end{array}$ & $\begin{array}{r}D_{\mathrm{O}_{2}, \mathrm{~N}_{2}}, \\
\mathrm{~cm}^{2} / \mathrm{s}\end{array}$ & $\begin{array}{r}D_{\mathrm{CO}_{2}, \mathrm{~N}_{2}}, \\
\mathrm{~cm}^{2} / \mathrm{s}\end{array}$ & $L / x_{f}$ \\
\hline 1000 & 2.38 & 1.86 & 2.13 \\
1100 & 2.70 & 2.11 & 2.13 \\
1200 & 3.03 & 2.38 & 2.13 \\
1300 & 3.38 & 2.65 & 2.13 \\
\hline
\end{tabular}


TABLE III Estimated oxide film thicknesses on slot or crack walls of SiC coating

\begin{tabular}{ccccc}
\hline $\begin{array}{c}\text { Temperature, } \\
{ }^{\circ} \mathrm{C}\end{array}$ & \multicolumn{2}{c}{ Rate constant } & \multicolumn{2}{c}{ Oxide thickness } \\
\cline { 2 - 5 } & $\begin{array}{c}1 \mathrm{~atm} \mathrm{O}_{2},{ }^{\mathrm{a}} \\
\mu \mathrm{m}^{2} / \mathrm{h}\end{array}$ & $\begin{array}{c}0.21 \mathrm{~atm} \mathrm{O}_{2}, \\
\mu \mathrm{m}^{2} / \mathrm{h}\end{array}$ & $\begin{array}{c}0.5 \mathrm{~h} \mathrm{in} 0.21 \mathrm{~atm} \mathrm{O}_{2}, \\
\mu \mathrm{m}\end{array}$ & $\begin{array}{c}2.5 \mathrm{~h} \mathrm{in} 0.21 \mathrm{~atm} \mathrm{O}_{2}, \\
\mu \mathrm{m}\end{array}$ \\
\hline 1200 & $1.82 \times 10^{-2}$ & $3.78 \times 10^{-3}$ & $4.35 \times 10^{-2}$ & $9.72 \times 10^{-2}$ \\
1300 & $3.76 \times 10^{-2}$ & $7.90 \times 10^{-3}$ & $6.28 \times 10^{-2}$ & 0.14 \\
\hline${ }^{a}$ From reference 23 & & & &
\end{tabular}

${ }^{\mathrm{a}}$ From reference 23. 
TABLE IV Measured and calculated radii of oxidation cavity for SiC-coated RCC specimens with machined slots

\begin{tabular}{|c|c|c|}
\hline $\begin{array}{l}\text { Width of slot, } \\
\mathrm{mm}\end{array}$ & $\begin{array}{l}\text { Measured } \\
\text { radius, } \\
\text { mm }\end{array}$ & $\begin{array}{c}\text { Calculated radius, }{ }^{\mathrm{a}} \\
r, \\
\mathrm{~mm}\end{array}$ \\
\hline \multicolumn{3}{|c|}{$0.5 \mathrm{~h}$ exposure } \\
\hline $0.26 \pm 0.02$ & $0.99 \pm 0.07$ & $1.82 \pm 0.07$ \\
\hline $0.53 \pm 0.02$ & $1.22 \pm 0.03$ & $2.60 \pm 0.05$ \\
\hline $0.81 \pm 0.02$ & $1.51 \pm 0.03$ & $3.32 \pm 0.04$ \\
\hline $1.08 \pm 0.01$ & $1.51 \pm 0.03$ & $3.77 \pm 0.02$ \\
\hline \multicolumn{3}{|c|}{$2.5 \mathrm{~h}$ exposure } \\
\hline $0.44 \pm 0.08$ & $2.38 \pm 0.01$ & $3.80 \pm 0.30$ \\
\hline $0.59 \pm 0.08$ & $2.60 \pm 0.16$ & $4.40 \pm 0.26$ \\
\hline $1.05 \pm 0.07$ & $2.96 \pm 0.04$ & $5.87 \pm 0.20$ \\
\hline
\end{tabular}

${ }^{\mathrm{a}}$ From equation (27). 
TABLE V Oxidation rates for SiC-coated

RCC specimens with machined slots

[At $T=1200^{\circ} \mathrm{C}$ in air.]

\begin{tabular}{lccc}
\hline \multicolumn{1}{c}{$\begin{array}{c}\text { Slot width, } \\
w, \\
\mathrm{~mm}\end{array}$} & $\begin{array}{c}\text { Slot length, } \\
l, \\
\mathrm{~mm}\end{array}$ & \multicolumn{2}{c}{$\begin{array}{c}\text { Weight loss rate, } \\
\mathrm{mg} / \mathrm{h} \cdot \mathrm{mm}^{2}\end{array}$} \\
\cline { 3 - 4 } & & Measured & Calculated $^{\mathrm{a}}$ \\
\hline $0.484 \pm 0.062$ & $8.177 \pm 0.923$ & $34 \pm 6$ & $55 \pm 10$ \\
$0.312 \pm 0.033$ & $8.284 \pm 0.63$ & $48 \pm 6$ & $55 \pm 10$ \\
$0.560 \pm 0.013$ & $7.094 \pm 0.132$ & $48 \pm 1$ & $55 \pm 10$ \\
$0.466 \pm 0.04$ & $7.114 \pm 0.019$ & $57 \pm 5$ & $55 \pm 10$ \\
$1.116 \pm 0.024$ & $7.602 \pm 0.101$ & $18 \pm 1$ & $55 \pm 10$ \\
$0.963 \pm 0.0041$ & $7.624 \pm 0.039$ & $21 \pm 1$ & $55 \pm 10$ \\
\hline${ }^{\mathrm{a}}$ From equation (24).
\end{tabular}

${ }^{\mathrm{a}}$ From equation (24). 
TABLE VI Measured and calculated rates of RCC oxidation through craze cracks

\begin{tabular}{|c|c|c|c|c|c|c|c|}
\hline $\begin{array}{l}\text { Sample temperature, } \\
{ }^{\circ} \mathrm{C}\end{array}$ & $\begin{array}{c}\text { Geometrical } \\
\text { surface area, } \\
\mathrm{mm}^{2}\end{array}$ & $\begin{array}{c}\text { Total crack } \\
\text { length, } \\
\text { mm }\end{array}$ & $\begin{array}{c}\text { Crack width, } \\
\mu \mathrm{m}\end{array}$ & $\begin{array}{l}\text { Area of carbon } \\
\text { exposed by } \\
\text { craze cracks, } \\
\mathrm{mm}^{2}\end{array}$ & $\begin{array}{l}\text { Calculated } \\
\text { linear rate, } \\
\mathrm{mg} / \mathrm{mm}^{2} \cdot \mathrm{hr}\end{array}$ & $\begin{array}{c}\text { Measured } \\
\text { linear rate, } \\
\mathrm{mg} / \mathrm{mm}^{2} \cdot \mathrm{hr}\end{array}$ & $\begin{array}{c}\text { Measured } \\
\text { parabolic rate, } \\
\mathrm{mg}^{2} / \mathrm{mm}^{4} \cdot \mathrm{hr}\end{array}$ \\
\hline Room temperature & & & $12.8 \pm 1.4$ & & & & \\
\hline 1000 & $850.2 \pm 10$ & $281 \pm 34$ & $10.2 \pm 2.7$ & $2.87 \pm 0.8$ & $50 \pm 9$ & $31 \pm 9$ & ----- \\
\hline 1100 & $935.5 \pm 10$ & $309 \pm 37$ & $8.7 \pm 2.3$ & $2.67 \pm 0.8$ & $53 \pm 9$ & $31 \pm 9$ & $3.94 \times 10^{-3}$ \\
\hline 1200 & $946.8 \pm 10$ & $312 \pm 37$ & $7.1 \pm 1.8$ & $2.21 \pm 0.6$ & $55 \pm 10$ & $53 \pm 15$ & $2.79 \times 10^{-2}$ \\
\hline 1300 & $940.2 \pm 10$ & $310 \pm 37$ & $5.5 \pm 1.4$ & $1.71 \pm 0.5$ & $57 \pm 10$ & $67 \pm 20$ & $3.25 \times 10^{-2}$ \\
\hline
\end{tabular}

${ }^{a}$ Equal to (geometrical area $\times$ crack length)/unit area.

${ }^{b}$ Equal to (total crack length) $\times($ crack width).

${ }^{c}$ From equation (24).

${ }^{\mathrm{d}}$ Area is exposed area of carbon/carbon.

${ }^{\mathrm{e}}$ Area is geometrical surface area. 
Fig. 1.- Reinforced carbon/carbon (RCC) sample.

Fig. 2. - Optical micrograph showing oxidation void in $\mathrm{RCC}$ formed below crack in SiC coating at $1100{ }^{\circ} \mathrm{C}$ and 0.0066 atm $(667$ Pa) for $1 \mathrm{~h}$.

Fig. 3.-Machined slots in RCC buttons.

Fig. 4.-Crack pattern on RCC disk. (a) Optical micrograph. (b) "Skeleton” trace of cracks.

Fig. 5.-Crack in SiC conversion coating.

Fig. 6.-Two-step diffusion control model [12]. (a) Schematic of fluxes and boundaries. (b) Relative concentrations of gases.

Fig. 7.-Plot to show relative contribution of Knudsen diffusivity to effective diffusivity. The vertical line shows average crack width.

Fig. 8. - Oxide film on surface of $\mathrm{SiC}$ coating $\left(0.5 \mathrm{~h}\right.$ in air at $\left.1200^{\circ} \mathrm{C}\right)$ at crack opening. (a) Electron micrograph. (b) Oxygen map.

Fig. 9.-Oxidation below nominal 0.25 - $\mathrm{mm}$ slots in $\mathrm{SiC}$ coating. (a) $0.28-\mathrm{mm}$ slot in air at $1200{ }^{\circ} \mathrm{C}$ for $0.5 \mathrm{~h}$. (b) $0.37-\mathrm{mm}$ slot in air at $1200{ }^{\circ} \mathrm{C}$ for $2.5 \mathrm{~h}$.

Fig. 10.-Computed tomography (CT) of machine-slotted SiC-coated RCC oxidized for $0.5 \mathrm{~h}$ in air at $1200^{\circ} \mathrm{C}$. (a) CT sample locations. (b) Three CT slices. Slot near notch on left is $0.76 \mathrm{~mm}$, and slot on right is $1.03 \mathrm{~mm}$. (c) Three-dimensional reconstruction of disk.

Fig. 11.-Oxidation kinetics determined from interrupted weight loss measurements for RCC specimen with 0.484-mm slot width at $1200^{\circ} \mathrm{C}$ in air.

Fig. 12.- Oxidation kinetics for RCC in air. (a) $1000^{\circ} \mathrm{C}$. (b) $1100{ }^{\circ} \mathrm{C}$. (c) $1200{ }^{\circ} \mathrm{C}$. (d) $1300{ }^{\circ} \mathrm{C}$.

Fig. 13.- Computed tomography (CT) of craze crack of SiC-coated RCC oxidized for $2.5 \mathrm{~h}$ in air at $1143^{\circ} \mathrm{C}$. (a) Location of CT slices. (b) Two CT slices. 